\title{
Effects of Motor Dual Task Training on Spatio- temporal Gait Parameters of Post-stroke Patients
}

\author{
Sunhwa Shim, MSc, OT ${ }^{1)}$, Jaeho Yu, PhD, $\mathrm{PT}^{2)}$, Jinhwa Jung, PhD, OT ${ }^{3)}$, \\ Hyungkyu Kang, MSc, $\mathrm{PT}^{4}$, $\mathrm{K}_{\text {Ihun }}$ Cho, MSc, $\mathrm{PT}^{5}$ ) \\ 1) Department of Occupational Therapy, Graduate School of Health Science, Yonsei University \\ 2) Department of Physical Therapy, Kangwon National University \\ 3) Department of Occupational Therapy, Semyung University \\ 4) Department of Physical Therapy, Sahmyook University \\ 5) Department of Physical Therapy, Seoul BukBu Hospital: 38 Yangwonnyeok-ro, Jungnang-gu, Seoul, \\ 131-230, Republic of Korea. \\ TEL: +82 2-2036-0270,FAX: +82 2-2036-0300,E-mail: mamiya34@naver.com
}

\begin{abstract}
Purpose] The purpose of this study was to investigate the effect of motor dual task training on gait ability of post-stroke patients. [Subjects] Participants were randomly allocated to 2 groups: a motor dual task training group ( $\mathrm{n}=17)$ and a control group $(\mathrm{n}=16)$. [Methods] Both groups received physical therapy for 30 minutes, 5 days per week for 6 weeks. The motor dual task training group received additional motor dual task training for 30 minutes, 3 days per week for 6 weeks. Gait ability was evaluated using the GAITRite system. [Results] Temporal parameters and spatial parameters were significantly improved by motor dual task training. Changes in gait speed, cadence, paretic step length, non-paretic step length, paretic stride length, non-paretic stride length, and paretic single limb support period were significantly different between the motor dual task training group and the control group. [Conclusion] Motor dual task training improved gait ability. These results suggest that motor dual task training is feasible and suitable for individuals with stroke.

Key words: Dual task, Stroke, Gait
\end{abstract}

(This article was submitted Apr. 3, 2012, and was accepted Apr. 26, 2012)

\section{INTRODUCTION}

Stroke is a cerebrovascular disease in which blockage or rupture occurs in the cerebrovascular area, obstructing blood flow, leading to damage of neurons or necrosis due to interruption of oxygen and nutrient supply. It is the most common form of acquired brain injury and results in disability and death throughout the world ${ }^{1)}$

The aspects of disability caused by stroke differ depending on the degree and location of brain injury, but generally include balance impairment, cognitive impairment, sensory impairment, mood impairment, and dysfunction of the upper and lower extremities, causing problems such as decrease in capacity for active exercise and loss of mobility ${ }^{2}$.

Functional recovery of hemiplegic stroke patients is associated with high costs and a high level of effort. However, even with therapy, long-term functional and physical disabilities can persist, and patients may show difficulty in independent walking when they return to their homes and communities ${ }^{3)}$. Recovery of walking ability, in particular, directly affects patients' attempts to return to their lifestyle before stroke, to live an independent life and to participate in social activities ${ }^{4}$; therefore, many studies have been carried out on various interventions for the recovery of independent walking ${ }^{5)}$.
Therapeutic approaches to walking improvement for stroke patients have included systematic therapeutic training methods such as virtual reality training ${ }^{6}$, force platform biofeedback ${ }^{7}$, and treadmill training ${ }^{8)}$. More recently, dual task training during which patients with neurologic damage, such as stroke, perform both motor tasks and cognitive tasks related to gait functions has become the main focus of research in this field ${ }^{9}$. Bowen et al. measured the gait parameters of 11 stroke patients in single task (walking) and dual task (listening and answering with walking) conditions, and reported a significant decrease in gait speed under dual task conditions compared to single task conditions ${ }^{10}$. A study by Haggard et al. reported that stride length of patients with neurological damage decreased by $7 \%$ unfer dual task conditions compared to a single task conditions ${ }^{11)}$. In addition, Dawes et al. reported that the interference caused by cognitive tasks that appears in patients with neurological damage is shown more clearly when the intensity of training is higher ${ }^{12)}$. Performing a motor task and a cognitive task at the same time is not difficult for healthy subjects ${ }^{13)}$, but for patients with neurological damage or elderly people whose attention is decreased, dual tasks can lower physical and cognitive function, causing falls ${ }^{14}$, and loss of gait ability ${ }^{10,11)}$. Yang et al. highlighted the cognitive-motor interference that can 
be caused by cognitive tasks in patients with neurological damage, and emphasized the importance of motor dual task training, in which 2 motor tasks are performed at the same time, over dual task training, in which a motor task and a cognitive task are performed at the same time ${ }^{15)}$. Handling several mobility tasks at the same time is an innate function for humans and is necessary for performing the activities of daily living. If a dual task is set as an indicator of assessment, it may play a role in helping patients with neurological damage to return to their communities ${ }^{16)}$. Therefore, this study sought to investigate the effects of motor dual task training on the temporal and spatial parameters of gait of stroke patients in order to develop a new therapeutic strategy for promoting mobility and improving the independent lives of stroke patients.

\section{SUBJECTS AND METHODS}

This study recruited 35 patients who were admitted to I hospital in Korea after being diagnosed with stroke. The subjects understood the contents of the study and agreed to participate. The inclusion criteria were as follows: presence of hemiparesis resulting from a single stroke that had occurred in the past 6 months; ability to communicate and understand with a Mini-Mental Status Examination score of over 24 points ${ }^{17)}$; no visual disorders or visual field deficits; no known musculoskeletal conditions that would affect patients' ability to safely walk, repeatedly; and ability to walk $10 \mathrm{~m}$ independently with or without an assistive device.

The study used a pretest-posttest control group design, and the subjects were divided into a motor dual task training (MDT) group and a control (CON) group by a computer program (Table 1). During the study, 1 patient from each of the 2 groups dropped out from the experiment due to a change in medical status, and 1 patient from the CON group dropped out because of discharge from hospital. Therefore, 17 patients were assessed in the MDT group, and 16 patients were assessed in the CON group.

The pretest was carried out before the intervention, and the posttest was performed after intervention. The MDT group and the CON group received in traditional physical therapy consisting of 10 minutes of range of motion exercises, 10 minutes of functional mobility training, and 10 minutes of gait training. This therapy was carried out one to one with a therapist for 30 minutes, 5 days per week for 6 weeks. The MDT group practiced motor dual task training for an additional 30 minutes, 3 days per week for 6 weeks. There were rest periods between each part of the training sessions so that the subjects did not become fatigued.

The motor dual task used in this study was applied after modifying and supplementing the task used by Yang et al. ${ }^{18)}$. The therapist held a $70 \mathrm{~cm}$-long stick with a ball attached to it by a string and walked next to the subject. The subject walked to a target point $10 \mathrm{~m}$ away while kicking the ball with the knee on the non-paretic side and returned to the start point while kicking the ball with the foot on the paretic side. While the subject walked to the target point kicking the ball with the non-paretic knee, the therapist held the ball at the height of the subject's ankle joint. The subject's gait speed
Table 1. Subject characteristics

\begin{tabular}{lcc}
\hline Parameters & MDT $(\mathrm{n}=17)$ & $\mathrm{CON}(\mathrm{n}=16)$ \\
\hline Gender & & \\
Male/Female & $12 / 5$ & $8 / 8$ \\
Paretic side & & \\
Right/Left & $14 / 3$ & $10 / 6$ \\
Age, years & $65.59(5.81)$ & $61.56(6.17)$ \\
Duration, months & $16.29(2.62)$ & $17.44(3.67)$ \\
Height, cm & $164.65(6.44)$ & $164.94(7.88)$ \\
Weight, kg & $63.37(9.78)$ & $61.50(7.21)$ \\
Br stages, score & $3.05(0.55)$ & $3.25(0.68)$ \\
MMSE, score & $25.35(2.50)$ & $27.06(2.98)$ \\
\hline
\end{tabular}

$(\mathrm{N}=33)$ NOTE. Values are mean (SD). Abbreviation: MDC, Motor dual task training group; CON, Control group; MMSE, Mini Mental State Examination; Br stages, Brunnstrom stages.

was inconsistent, following the speed of the ball that the therapist was holding. The ball used was a Styrofoam ball $18 \mathrm{~cm}$ in diameter, and the total gait distance was $20 \mathrm{~m}$ back and forth. After 13 minutes of training, the subject rested for 4 minutes and then trained again for another 13 minutes. The therapist checked on the status of the subject after every $20 \mathrm{~m}$ of training, and assessed whether the subject could follow the moving speed of the ball. The level of difficulty of the task was controlled, with training for 1-2 weeks on a straight course, training after 3-4 weeks on an S-shaped course, and training after 5-6 weeks on an obstacle course.

Gait abilities were measured using an electrical walkway system (GAITRite, CIR System Inc., USA). The system captures temporal and spatial gait parameters. It consists of an $810 \times 89 \times 0.625 \mathrm{~cm}$ (length $\times$ width $\times$ height $)$ instrumented mat with 27,648 embedded pressure sensitive sensors, spaced at $1.27 \mathrm{~cm}$, arranged in a $48 \times 576$ grid. The sampling rate was $80 \mathrm{~Hz}$. Data were input to a computer and analyzed using gait analysis software (GAITRite GOLD, version $3.2 b)$. Subjects were asked to walk at a comfortable gait speed comfortable in all 3 trials. Subjects initiated and terminated walking a minimum of $3 \mathrm{~m}$ from the start and end of the walkway to maintain gait speed on the mat. A verbal command was given to initiate walking and one of the examiners accompanied the subject to prevent a fall during walking. Gait speed, cadence, step length, stride length, single limb support period, and double limb support period for both the paretic and non-paretic legs were measured.

Statistical analyses were performed using SPSS version 18.0 software. After confirming the normality of the data with the Shapiro-Wilks test, pre- and post-intervention data were examined with the paired t-test within each group of subjects and with the independent t-test between the groups. The level of significance was chosen as $5 \%$ for all statistical analyses.

\section{RESULTS}

Compared to pre-intervention values, the temporal parameters (gait speed and cadence) and spatial parameters 
Table 2. Comparison of temporal gait measures within groups and between groups

\begin{tabular}{lcccccc}
\hline & \multicolumn{3}{c}{ Values } & \multicolumn{2}{c}{ Change Values } \\
\cline { 2 - 7 } Parameters & \multicolumn{2}{c}{ MDT $(\mathrm{n}=17)$} & CON $(\mathrm{n}=16)$ & MDT $(\mathrm{n}=17)$ & CON $(\mathrm{n}=16)$ \\
\cline { 2 - 6 } & \multicolumn{1}{c}{ Pre } & Post & Pre & Post & Post-Pre & Post-Pre \\
\hline $\begin{array}{l}\text { Speed } \\
(\mathrm{cm} / \mathrm{s})\end{array}$ & $47.84(17.28)$ & $64.55(24.01)^{* * *}$ & $50.36(18.00)$ & $55.86(19.73)^{* *}$ & $16.71(8.50)$ & $5.50(5.13)^{* * *}$ \\
$\begin{array}{l}\text { Cadence } \\
\text { (steps/min) }\end{array}$ & $77.41(23.47)$ & $91.14(21.34)^{* * *}$ & $77.18(17.60)$ & $81.74(16.27)^{* *}$ & $13.73(9.16)$ & $4.56(6.45)^{* *}$ \\
\hline
\end{tabular}

$(\mathrm{N}=33)$ NOTE. Values are mean (SD). Abbreviation: MDT, Motor dual task training group; CON, Control group; P, paretic side; NP, non-paretic side; Post-Pre, posttest-pretest. ${ }^{* *} \mathrm{p}<0.01,{ }^{* * *} \mathrm{p}<0.001$

Table 3. Comparison of spatial gait measures within groups and between groups

\begin{tabular}{|c|c|c|c|c|c|c|c|}
\hline \multirow{3}{*}{ Parameters } & & \multicolumn{4}{|c|}{ Values } & \multicolumn{2}{|c|}{ Change Values } \\
\hline & & \multicolumn{2}{|c|}{ MDT $(n=17)$} & \multicolumn{2}{|c|}{$\mathrm{CON}(\mathrm{n}=16)$} & \multirow{2}{*}{$\begin{array}{c}\text { MDT }(n=17) \\
\text { Post-Pre }\end{array}$} & \multirow{2}{*}{$\frac{\mathrm{CON}(\mathrm{n}=16)}{\text { Post-Pre }}$} \\
\hline & & Pre & Post & Pre & Post & & \\
\hline \multirow{2}{*}{ Step length (cm) } & $\mathrm{P}$ & $38.62(7.61)$ & $44.19(7.68)^{* * *}$ & $40.79(6.77)$ & $43.38(7.06)^{* *}$ & $5.57(4.55)$ & $2.59(2.73)^{*}$ \\
\hline & NP & $33.80(8.97)$ & $41.78(13.12)^{* *}$ & $35.78(8.03)$ & $37.57(8.25)^{* *}$ & $7.99(10.37)$ & $1.79(1.91)^{*}$ \\
\hline \multirow{2}{*}{ Stride length $(\mathrm{cm})$} & $\mathrm{P}$ & $71.24(15.84)$ & $86.03(19.77)^{* * *}$ & $76.66(13.64)$ & $78.00(14.07)^{* *}$ & $14.80(9.92)$ & $3.36(3.66)^{* * *}$ \\
\hline & NP & $69.99(19.98)$ & $86.27(20.30)^{* * *}$ & $76.72(13.97)$ & $80.84(14.64)^{* * *}$ & $16.28(10.44)$ & $4.12(3.47)^{* * *}$ \\
\hline \multirow{2}{*}{$\begin{array}{l}\text { Single limb } \\
\text { support period (\%) }\end{array}$} & $\mathrm{P}$ & $28.32(5.90)$ & $32.04(5.49)^{* * *}$ & $25.81(5.55)$ & $27.68(4.88)^{* * *}$ & $3.72(3.15)$ & $1.86(1.61)^{*}$ \\
\hline & NP & $34.77(4.41)$ & $36.64(2.73)^{*}$ & $34.46(5.97)$ & $36.38(4.93)^{*}$ & $1.86(3.29)$ & $1.93(2.91)$ \\
\hline \multirow{2}{*}{$\begin{array}{l}\text { Double limb } \\
\text { support period (\%) }\end{array}$} & $\mathrm{P}$ & $38.65(7.73)$ & $34.41(6.25)^{* * *}$ & $39.28(10.14)$ & $35.93(9.28)^{* * *}$ & $-4.28(3.54)$ & $-3.34(2.94)$ \\
\hline & NP & $38.59(7.44)$ & $34.78(6.53)^{* * *}$ & $39.33(10.10)$ & $35.81(8.48)^{* * *}$ & $-4.09(3.62)$ & $-3.52(2.71)$ \\
\hline
\end{tabular}

$(\mathrm{N}=33)$ NOTE. Values are mean (SD). Abbreviation: MDT, Motor dual task training group; CON, Control group; P, paretic side; NP, non-paretic side; Post-Pre, posttest-pretest. ${ }^{*} \mathrm{p}<0.05,{ }^{* *} \mathrm{p}<0.01,{ }^{* * *} \mathrm{p}<0.001$

(step length, stride length, and single limb support period for both the paretic and non-paretic legs) after the of 6 weeks of intervention had significantly increased in both groups $(\mathrm{p}<0.05)$. Furthermore, the spatial parameters of the paretic double limb support period and non-paretic double limb support period significantly decreased in both groups, compared to pre-intervention $(\mathrm{p}<0.05)$.

Changes in gait speed, cadence, paretic step length, non-paretic step length, paretic stride length, non-paretic stride length, and paretic single limb support period were significantly different between the MDT group and the CON group $(\mathrm{p}<0.05)$ (Tables 2, 3).

\section{DISCUSSION}

Gait is a complex process during which much of the nervous system and musculoskeletal system are used, and is a continuous and repetitive process that ambulates the body ${ }^{19)}$. Stroke patients have a characteristic gait pattern with a slow gait cycle and gait speed, different stride length between the affected side and the non-affected side, short stance phase on the affected side, and a relatively long swing phase $^{20)}$. During abnormal walking, a shortened weightsupporting time of the lower extremity on the affected side is usually seen, and balance control during gait becomes difficult due to a prolonged period of double limb support, leading to a decline in energy efficiency ${ }^{21)}$. Thus, gait speed assessment can be used as a criterion of functional recovery for stroke patients. The standard of independent gait ability ${ }^{22}$ and increase in gait speed are the final steps of stroke rehabilitation, providing the chance for stroke patients to return to their community and actively participate in social activities ${ }^{23)}$.

In this study, motor dual task training consisted of 2 motor tasks for the improvement of gait of stroke patients. Training was conducted for 6 weeks, and gait speed, cadence, paretic and non-paretic side step length, stride length, single limb support period, and double limb support period were measured. The results show that the gait speed of the MDT group increased from $47.84 \mathrm{~cm} / \mathrm{s}$ to $64.55 \mathrm{~cm} / \mathrm{s}$ and that the gait speed of the CON group increased from $50.35 \mathrm{~cm} / \mathrm{s}$ to $55.85 \mathrm{~cm} / \mathrm{s}$, with both groups showing significant improvements $(\mathrm{p}<0.05)$. When the improvements were compared between the groups, a significantly better improvement was observed in the MDT group $(\mathrm{p}<0.05)$. Among previous studies conducted of gait ability, a study in which chronic stroke patients practiced 7 types of dual task training using balls for 4 weeks demonstrated a change in gait speed from $52 \mathrm{~cm} / \mathrm{s}$ to $69 \mathrm{~cm} / \mathrm{s}$, an increase of $17 \mathrm{~cm} / \mathrm{s}^{6}$. According to the results of a study on the relationship between gait speed of stroke patients and their activities during daily living, a speed of $40 \mathrm{~cm} / \mathrm{s}$ is required for living at home, a speed of $58-80 \mathrm{~cm} / \mathrm{s}$ is required for restricted social activities, and a speed above $80 \mathrm{~cm} / \mathrm{s}$ is required for social activities ${ }^{24}$. In the current study, the gait speed of the MDT group increased from $47.84 \mathrm{~cm} / \mathrm{s}$ to $64.55 \mathrm{~cm} / \mathrm{s}$. This result is meaningful 
because the final speed is within the speed of $58-80 \mathrm{~cm} / \mathrm{s}$ required for performing restricted social activities, and suggests that motor dual task training can help stroke patients return to their community and daily activities.

For hemiplegic stroke patients, the weight-bearing duration on the affected side is shortened and the double limb support period is increased; thus, gait cycle and cadence become slow ${ }^{25)}$. In addition, when gait is unstable, stride length decreases and the gap between gaits increases, increasing cadence. Also, the single limb support period decreases, and the double limb support period increases ${ }^{26)}$. In the present study, after 6 weeks of training, both groups showed significant increases in cadence, step length of the paretic and non-paretic sides, stride length, and single limb support period $(\mathrm{p}<0.05)$, and a significant decrease in double limb support period $(\mathrm{p}<0.05)$. Furthermore, when comparing the groups, the MDT group showed a significantly better improvement in cadence, step length of the paretic and non-paretic sides, stride length, and single limb support period on the affected side. Increased neuroplasticity and brain reorganization in response to repeated task-oriented training improves the gait function of stroke patients through motor re-learning ${ }^{27}$. The motor dual task training used in this study was conducted in such a manner that the subject walked while targeting a ball that the therapist controlled, and the subject kicked the ball with the non-paretic knee and paretic foot while walking. The process of kicking the ball with the non-paretic knee induces improvement in the single limb support period of the paretic lower extremity, and the process of kicking ball with the paretic foot induces improvement in the step length and stride length of the paretic lower extremity, leading to improvement in the cadence of the subjects.

This study investigated the effect of motor dual task training on the gait ability of stroke patients, and the results show that motor dual task training is an effective form of training that improves the functional mobility of stroke patients by improving their gait abilities. This type of training can be actively utilized in physical therapy clinics.

The limitation of this study is that its results cannot be generalized to all stroke patients because subjects with very good gait abilities or very bad gait abilities were excluded. In addition, the subjects' daily living activities were not completely limited during the study period; therefore, the effect of daily living activity on the change in gait ability observed cannot be completely excluded.

\section{REFERENCES}

1) Duncan PW, Goldstein LB, Horner RD, et al.: Similar motor recovery of upper and lower extremities after stroke. Stroke, 1994, 25: 1181-1188. [Medline] [CrossRef]

2) de Weerdt W, Lincoln NB, Harrison MA: Prediction of arm and hand function recovery in stroke patients. Int J Rehabil Res, 1987, 10: 110-112. [Medline]

3) Patel MD, Tilling K, Lawrence E, et al.: Relationships between long-term stroke disability, handicap and health-related quality of life. Age Ageing, 2006, 35: 273-279. [Medline] [CrossRef]

4) Taylor D, Stretton CM, Mudge S, et al.: Does clinic-measured gait speed differ from gait speed measured in the community in people with stroke?
Clin Rehabil, 2006, 20: 438-444. [Medline] [CrossRef]

5) Zinn S, Dudley TK, Bosworth HB, et al.: The effect of poststroke cognitive impairment on rehabilitation process and functional outcome. Arch Phys Med Rehabil, 2004, 85: 1084-1090. [Medline] [CrossRef]

6) Jaffe DL, Brown DA, Pierson-Carey CD, et al.: Stepping over obstacles to improve walking in individuals with poststroke hemiplegia. J Rehabil Res Dev, 2004, 41: 283-292. [Medline] [CrossRef]

7) Yavuzer G, Eser F, Karakus D, et al.: The effects of balance training on gait late after stroke: a randomized controlled trial. Clin Rehabil, 2006, 20 960-969. [Medline] [CrossRef]

8) Macko RF, Ivey FM, Forrester LW, et al.: Treadmill exercise rehabilitation improves ambulatory function and cardiovascular fitness in patients with chronic stroke: a randomized, controlled trial. Stroke, 2005, 36: 2206-2211. [Medline] [CrossRef]

9) Plummer-D'Amato P, Altmann LJ, Saracino D, et al.: Interactions between cognitive tasks and gait after stroke: a dual task study. Gait Posture, 2008, 27: 683-688. [Medline] [CrossRef]

10) Bowen A, Wenman R, Mickelborough J, et al.: Dual-task effects of talking while walking on velocity and balance following a stroke. Age Ageing, 2001, 30: 319-323. [Medline] [CrossRef]

11) Haggard P, Cockburn J, Cock J, et al.: Interference between gait and cognitive tasks in a rehabilitating neurological population. J Neurol Neurosurg Psychiatry, 2000, 69: 479-486. [Medline] [CrossRef]

12) Dawes H, Cockburn J, Roach NK, et al.: The effect of a perceptual cognitive task on exercise performance: the dual-task condition after brain injury. Clin Rehabil, 2003, 17: 535-539. [Medline] [CrossRef]

13) Brauer SG, Woollacott M, Shumway-Cook A: The interacting effects of cognitive demand and recovery of postural stability in balance-impaired elderly persons. J Gerontol A Biol Sci Med Sci, 2001, 56: M489-M496. [Medline] [CrossRef]

14) Beauchet O, Dubost V, Herrmann F, et al.: Relationship between dual-task related gait changes and intrinsic risk factors for falls among transitional frail older adults. Aging Clin Exp Res, 2005, 17: 270-275. [Medline]

15) Yang YR, Chen YC, Lee CS, et al.: Dual-task-related gait changes in individuals with stroke. Gait Posture, 2007, 25: 185-190. [Medline] [CrossRef]

16) Brauer SG, Morris ME: Can people with Parkinson's disease improve dual tasking when walking? Gait Posture, 2010, 31: 229-233. [Medline] [CrossRef]

17) Folstein MF, Folstein SE, McHugh PR: "Mini-mental state". A practical method for grading the cognitive state of patients for the clinician. J Psychiatr Res, 1975, 12: 189-198. [Medline] [CrossRef]

18) Yang YR, Wang RY, Chen YC, et al.: Dual-task exercise improves walking ability in chronic stroke: a randomized controlled trial. Arch Phys Med Rehabil, 2007, 88: 1236-1240. [Medline] [CrossRef]

19) Perry J, Garrett M, Gronley JK, et al.: Classification of walking handicap in the stroke population. Stroke, 1995, 26: 982-989. [Medline] [CrossRef]

20) Suzuki K, Yamada Y, Handa T, et al.: Relationship between stride length and walking rate in gait training for hemiparetic stroke patients. Am J Phys Med Rehabil, 1999, 78: 147-152. [Medline] [CrossRef]

21) Winstein CJ, Gardner ER, McNeal DR, et al.: Standing balance training: effect on balance and locomotion in hemiparetic adults. Arch Phys Med Rehabil, 1989, 70: 755-762. [Medline]

22) Hill K, Ellis P, Bernhardt J, et al.: Balance and mobility outcomes for stroke patients: a comprehensive audit. Aust J Physiother, 1997, 43: 173-180. [Medline]

23) Ng MF, Tong RK, Li LS: A pilot study of randomized clinical controlled trial of gait training in subacute stroke patients with partial bodyweight support electromechanical gait trainer and functional electrical stimulation: six-month follow-up. Stroke, 2008, 39: 154-160. [Medline] [CrossRef]

24) Lord SE, McPherson K, McNaughton HK, et al.: Community ambulation after stroke: how important and obtainable is it and what measures appear predictive? Arch Phys Med Rehabil, 2004, 85: 234-239. [Medline] [CrossRef]

25) Wagenaar RC, Beek WJ: Hemiplegic gait: a kinematic analysis using walking speed as a basis. J Biomech, 1992, 25: 1007-1015. [Medline] [CrossRef]

26) Patla A: A Framework for Understanding Mobility Problems in the Elderly. St.Louis: Mosby Year-book, 1995

27) Harvey RL: Improving poststroke recovery: neuroplasticity and taskoriented training. Curr Treat Options Cardiovasc Med, 2009, 11: 251-259. [Medline] [CrossRef] 